\title{
Rehabilitation evaluation model of a rehabilitation robot Based on fuzzy comprehensive evaluation
}

\author{
CHEN Lei \\ College of Mechanical Engineering \\ ,Sichuan university of Science and Engineering \\ Zigong city, Sichuan province 643000, China \\ e-mail: clstones999@sina.com \\ YANG Chang-niu, \\ College of Mechanical Engineering \\ ,Sichuan university of Science and Engineering \\ Zigong city, Sichuan province 643000 , China \\ e-mail: yangchangniu@sohu.com \\ HUANG Wen-quan, \\ College of Mechanical Engineering \\ ,Sichuan university of Science and Engineering
}

\author{
Zigong city, Sichuan province 643000 , China \\ e-mail: hwqse@163.com \\ SUN Ze-gang \\ College of Mechanical Engineering \\ ,Sichuan university of Science and Engineering \\ Zigong city, Sichuan province 643000, China \\ e-mail:szg527@126.com \\ Liu Yu-cong \\ College of Mechanical Engineering \\ ,Sichuan university of Science and Engineering \\ Zigong city, Sichuan province 643000 , China \\ e-mail: chinalliu@sina.com
}

\begin{abstract}
To solve rehabilitation evaluation problem of rehabilitation training, rehabilitation evaluation method based on fuzzy comprehensive evaluation was presented for 6-DOF wearable lower limb rehabilitation robot. Relative degradation degree was introduced to represent the transformation of the actual state of rehabilitation training and the very poor rehabilitation; Membership functions of relative degradation degrees for the rest of the quantitative and qualitative indicators were built by using the fuzzy statistical test method and fuzzy distribution. On the basis, Rehabilitation evaluation model was built based on fuzzy comprehensive evaluation, each layer of which was evaluated respectively, and suggests rehabilitation evaluation results of a lower limb rehabilitation robot. The instance analysis shows that the method is reasonable and effective.
\end{abstract}

Keywords-rehabilitative robot; rehabilitation evaluation; fuzzy comprehensive evaluation

\section{INTRODUCTION}

A lower limb rehabilitation robot is an important branch of a rehabilitation medical robot, developed by the motor nerve rehabilitation treatment technology in recent years ${ }^{[1]}$, which has become a research hotspot in the field of robot. Rehabilitation evaluation is an important part in rehabilitation process, and to assist a rehabilitation doctor acquire a patient's rehabilitation level based on the current information collection and analysis comparing with standard medical health. The problems of traditional rehabilitation ${ }^{1}$ evaluation method are simple measures, processing result simply and single evaluation conclusion ${ }^{[2]}$. It is difficult to accurately reflect the real patients' recovery level because of Human factors, and various evaluation factors are not weighted and ordered, so the evaluation results can't reflect the rehabilitation level of step-by-step, and there is no

Supported by The Fund of Sichuan provincial key laboratories( No.NJ2012-12) difference after rehabilitation therapy ${ }^{[3,4]}$, which causes negative rehabilitation therapy psychology. This paper presents a lower limb rehabilitation robot rehabilitation evaluation method, the rehabilitation evaluation indicator model is built based on fuzzy comprehensive evaluation method, and the calculation of the rehabilitation evaluation is accomplished, so as to realize the real time of rehabilitation training mode change of a lower limb rehabilitation robot, and maximize the scientific treatment of the patient's limb correctly.

\section{SELECTIONS OF THE REHABILITATION EVALUATION FACTORS}

To reflect truly the rehabilitation work state of the lower limb rehabilitation robot, considering the maneuverability of which, this paper choices six variables based on joint range of motion, muscle strength, muscle tension, motion control, reflex activity and the surface muscle signal. Fig.1 shows the hierarchical evaluation indicator system of the lower limb rehabilitation robot rehabilitation evaluation.

\section{ESTABLISHMENT OF THE FUZZY COMPREHENSIVE EVALUATION MODEL}

\section{A. Establishment of the evaluation indicator system}

Fig.1 shows the analysis diagram of a lower limb rehabilitation robot rehabilitation evaluation factor, which is hierarchical evaluation indicator system of rehabilitation, the target layer can be divided into four evaluation projects: $U x=\left(U x_{1}, U x_{2}, U x_{3}, U x_{4}\right)$, the project layer is divided into the next level component, which is the last level of indicator layer. For example, joint mobility can be divided into: $^{U x_{1}}=\left(U x_{11}, U x_{12}, U x_{13}\right)$.

\section{B. Establishment of evaluation set}

On the basis of the evaluation indicator system of rehabilitation, rehabilitation evaluation of the limb 
rehabilitation robot was divided into four fields with fuzzy comprehensive evaluation method:

$$
\begin{aligned}
& V=\left(V_{1}, V_{2}, V_{3}, V_{4}\right), V_{1}=\text { "verywell" } V_{2}=\text { "well" } \\
& V_{3}=\text { "bad" } V_{4}=\text { "worse" }
\end{aligned}
$$

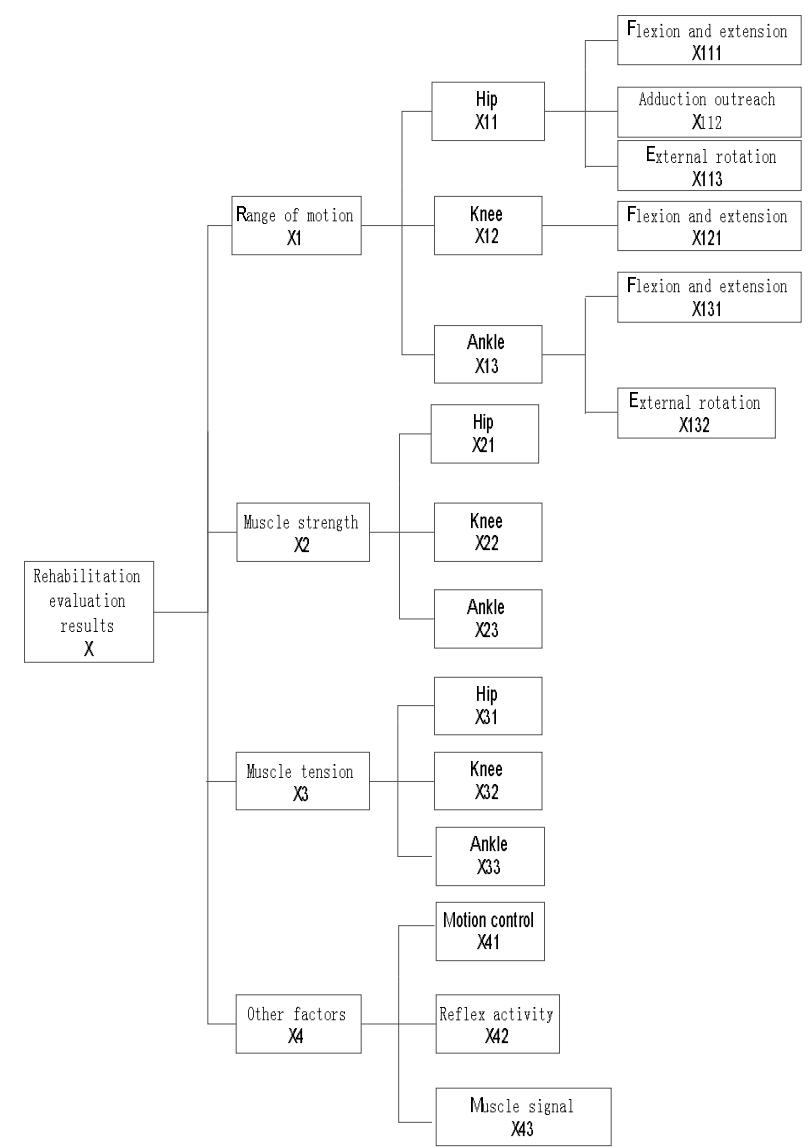

Fig.1 Rehabilitation evaluation indicators system

\section{Establishment of fuzzy evaluation matrix}

Fuzzy evaluation matrix is established by taking into the indicators to evaluate rehabilitation of lower limb rehabilitation robot evaluation. The membership of the evaluation sets is $r_{i j}(j=1,2,3,4)$, and membership set is $R_{i}=\left\{r_{i 1}, r_{i 2}, r_{i 3}, r_{i 4}\right\}$. For example, evaluation matrix of hip range of motion is as follows:

$$
R_{x_{11}}=\left[\begin{array}{c}
R_{x_{111}} \\
R_{x_{112}} \\
R_{x_{113}}
\end{array}\right]=\left[\begin{array}{llll}
r_{11} & r_{12} & r_{13} & r_{14} \\
r_{21} & r_{22} & r_{23} & r_{24} \\
r_{31} & r_{32} & r_{33} & r_{34}
\end{array}\right]
$$

The same fuzzy evaluation matrix of the indicator layer and project layer can be obtained, finally can get all the fuzzy comprehensive evaluation matrix of project layer
( $k$ is the layers of project number), such as the judgment matrix of the motion :

$$
R_{x_{1}}=\left[\begin{array}{c}
R_{x_{11}} \\
R_{x_{12}} \\
R_{x_{13}}
\end{array}\right]=\left[\begin{array}{llll}
\omega_{11} & \omega_{12} & \omega_{13} & \omega_{14} \\
\omega_{21} & \omega_{22} & \omega_{23} & \omega_{24} \\
\omega_{31} & \omega_{32} & \omega_{33} & \omega_{34}
\end{array}\right]
$$

\section{Determination of the weights of evaluation factors at different levels}

After rehabilitation evaluation system is established, the corresponding weights are given by the level indicators and the relative importance. On basis of expert consultation, the various indicators of the complex system are divided into interconnected orderly arrangement by AHP .Considering that the research of the lower limb rehabilitation robot in our country is still in early stages, to obtain a clear recovery evaluation results is more difficult. So the aid of expert experience is needed, and to assign various indicators is by the analytic hierarchy process, as shown in Table 1.

Using the data in table 1 by the improved method ${ }^{[5],}$ the optimal transfer matrix is calculated and meets the consistency requirements. The relative weight of each purpose component indicator weight can be directly calculated. The calculation results is as shown in table 2 .

To reflect the actual situation of the lower limb rehabilitation robot rehabilitation evaluation, the weighted average model of fuzzy comprehensive evaluation ${ }^{[6]}$ is chosen. Expression is:

$$
b_{j}=\sum_{i=1}^{n} a_{i} r_{i j}(j=1,2 \cdots, n)
$$

\section{ESTABLISHMENT OF MEMBERSHIP FUNCTION OF THE INDICATORS LAYER}

\section{A. Membership function of joint range of motion}

A fuzzy distribution method is used for the quantitative data of the indicators ${ }^{[7]}$. The triangular membership function is relatively simple, and other complex subordinate function results is smaller difference ${ }^{[8]}$.so the triangle and half trapezoid distribution function is chosen, and establish membership function of each indicator for different conditions as shown in figure 2 .

\section{B. Determination of membership degrees of Muscle, muscle tension, motion control and reflex activity}

A fuzzy statistical method is adopted based on the expert investigation: the experts on the basis of evaluation objects and the evaluation indicator is given, determine the membership degree of each evaluation factor and single factor evaluation matrix is obtained.

Membership $=\frac{\text { the number of evaluation experts }}{\text { The total number of eligible experts }}$ 


\begin{tabular}{|c|c|c|c|c|c|c|c|c|}
\hline $\begin{array}{l}\text { Expert } \\
\text { Number }\end{array}$ & $X 1$ & $X_{2}$ & $x 3$ & $\mathrm{X} 4$ & $\mathrm{X} 11$ & $X 12$ & $X 13$ & $X 21$ \\
\hline E1 & 1 & 2 & 1 & $1 / 3$ & 2 & 1 & 2 & 4 \\
\hline E2 & 1 & 1 & 1 & $1 / 3$ & 2 & 1 & 2 & 3 \\
\hline E3 & 2 & 1 & 1 & $1 / 4$ & 2 & 2 & 1 & 3 \\
\hline E4 & 1 & 2 & 1 & $1 / 3$ & 1 & 2 & 2 & 2 \\
\hline E5 & 1 & 1 & 1 & $1 / 4$ & 2 & 2 & 1 & 3 \\
\hline $\begin{array}{l}\text { Expert } \\
\text { Number }\end{array}$ & $X_{22}$ & $\times 23$ & $\times 31$ & $\times 32$ & X33 & $X 41$ & $X 42$ & $\times 43$ \\
\hline E1 & 2 & 2 & 3 & 2 & 2 & 3 & 2 & 2 \\
\hline E2 & 2 & 3 & 3 & 2 & 3 & 3 & 2 & 3 \\
\hline E3 & 3 & 1 & 4 & 3 & 3 & 4 & 1 & 2 \\
\hline E4 & 2 & 2 & 3 & 2 & 2 & 4 & 2 & 2 \\
\hline E5 & 2 & 3 & 3 & 3 & 2 & 3 & 1 & 3 \\
\hline $\begin{array}{l}\text { Expert } \\
\text { Number }\end{array}$ & X111 & $\mathrm{X} 112$ & $X 113$ & $\mathrm{X} 121$ & $X 131$ & $X 132$ & & \\
\hline E1 & 3 & 2 & 3 & 3 & 3 & 2 & & \\
\hline E2 & 4 & 1 & 2 & 3 & 4 & 2 & & \\
\hline E3 & 3 & 2 & 2 & 2 & 3 & 3 & & \\
\hline E4 & 4 & 2 & 3 & 3 & 3 & 2 & & \\
\hline E5 & 3 & 1 & 2 & 4 & 3 & 2 & & \\
\hline
\end{tabular}

Table 1 Weights of every indicator assigned by experts

\begin{tabular}{|c|c|c|c|}
\hline Indicator & $\begin{array}{l}\text { Weights of the } \\
\text { straton indicators }\end{array}$ & Indicator & $\begin{array}{l}\text { Weights of the } \\
\text { straton Indicators }\end{array}$ \\
\hline$x$ & $\begin{array}{l}0.28050 .3216 \\
0.2908 \quad 0.1071\end{array}$ & $X 4$ & $\begin{array}{l}0.45130 .2880 \\
0.2607\end{array}$ \\
\hline$x_{1}$ & $\begin{array}{l}0.43090 .2381 \\
0.3610\end{array}$ & $X 11$ & $\begin{array}{l}0.38050 .2812 \\
0.3483\end{array}$ \\
\hline$\times 2$ & $\begin{array}{l}0.51080 .2413 \\
0.2479\end{array}$ & $X 13$ & $0.6126 \quad 0.3874$ \\
\hline$x 3$ & $\begin{array}{l}0.4832 \quad 0.2741 \\
0.2427\end{array}$ & & \\
\hline
\end{tabular}

Table 2 Weights table of every indicator

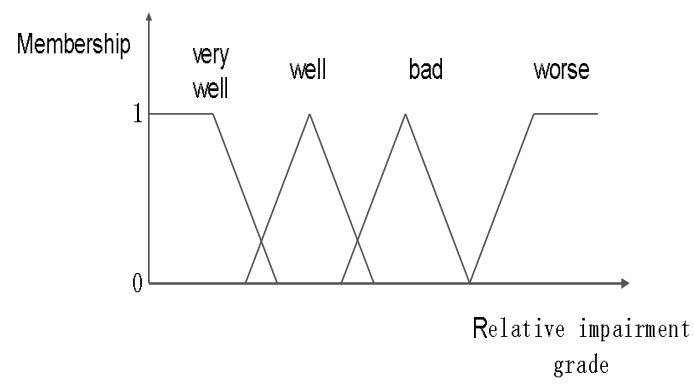

Fig.2 Distribution map of half-ladder-shaped an triangular membership function

\section{EXAMPLE ANALYSIS}

In patients in rehabilitation training under a certain type of lower limb rehabilitation robot assisted as, for example: the hip flexion is $65^{\circ}$ and adduction is $40^{\circ}$, knee extension torque $65^{\circ}$, and ankle plantar flexion torque $10^{\circ}$ and internal rotation $50^{\circ}$.

According to the introduced method of determining the membership function, to respectively determine the membership function of evaluation factors on the four kinds of evaluation, and into the actual value conclusion the membership degree of each factor, the judgment matrix can be calculated. For example, The judgment matrix of hip flexion and extension is:

$$
\begin{gathered}
R_{111}=\left[\begin{array}{llll}
1 & 0 & 0 & 0
\end{array}\right] \\
R_{x_{11}}=\left[\begin{array}{cccc}
1 & 0 & 0 & 0 \\
0 & 0.415 & 0.585 & 0 \\
0 & 0.325 & 0.675 & 0
\end{array}\right] \\
R_{x_{13}}=\left[\begin{array}{llll}
0 & 0.225 & 0.775 & 0 \\
0 & 0.430 & 0.570 & 0
\end{array}\right]
\end{gathered}
$$

Combined with the weight, then:

$$
B_{x_{1}}=A_{x_{1}} \circ R_{x_{1}}=\left[\begin{array}{llll}
0.4015 & 0.2026 & 0.3959 & 0
\end{array}\right]
$$

The rest factors evaluation matrix is obtained by the fuzzy statistical method :

$$
\begin{gathered}
R_{x_{2}}=\left[\begin{array}{cccc}
0.2 & 0.4 & 0.2 & 0 \\
0.3 & 0.45 & 0.25 & 0 \\
0.15 & 0.45 & 0.40 & 0
\end{array}\right], \\
R_{x_{3}}=\left[\begin{array}{cccc}
0.15 & 0.6 & 0.25 & 0 \\
0.2 & 0.5 & 0.3 & 0 \\
0.3 & 0.6 & 0.1 & 0
\end{array}\right] \\
R_{x_{4}}=\left[\begin{array}{cccc}
0.1 & 0.7 & 0.2 & 0 \\
0.15 & 0.6 & 0.25 & 0 \\
0.2 & 0.6 & 0.2 & 0
\end{array}\right]
\end{gathered}
$$

Combined with the weight, then:

$$
\begin{aligned}
& B_{x_{2}}=A_{x_{2}} \circ R_{x_{2}}=\left[\begin{array}{llll}
0.3015 & 0.5215 & 0.1770 & 0
\end{array}\right] \\
& B_{x_{3}}=A_{x_{3}} \circ R_{x_{3}}=\left[\begin{array}{llll}
0.1985 & 0.5863 & 0.2152 & 0
\end{array}\right] \\
& B_{x_{4}}=A_{x_{4}} \circ R_{x_{4}}=\left[\begin{array}{llll}
0.3375 & 0.6152 & 0.0573 & 0
\end{array}\right]
\end{aligned}
$$
is: 


$$
\begin{aligned}
R_{x} & =\left[\begin{array}{llll}
0.4015 & 0.2026 & 0.3959 & 0 \\
0.3015 & 0.5215 & 0.1770 & 0 \\
0.1985 & 0.5863 & 0.2152 & 0 \\
0.3375 & 0.6152 & 0.0573 & 0
\end{array}\right] \\
B_{x} & =A_{x} \circ R_{x}=\left[\begin{array}{llll}
0.2991 & 0.4655 & 0.2354 & 0
\end{array}\right]
\end{aligned}
$$

From the rehabilitation evaluation results, membership degree of well condition is bigger other than other condition of membership degree. Determine the rehabilitation status is general with the maximum membership degree method. From the membership degree of overall performance, the membership degrees respectively well and bad condition are 0.2991 and 0.354 , "verywell" condition is significantly higher than "bad" condition. Comparing with the actual situation, as rehabilitation training, the patient's limb will recover gradually and presents a step by step, until achieve medical health standard. So the rehabilitation evaluation method is reasonable and effective.

\section{CONCLUDING REMARKS}

Example analysis indicates that the established fuzzy evaluation model of lower limb rehabilitation robot rehabilitation evaluation is objectively accurate quantitative evaluation, and good operability, which can provide reference basis for patients in rehabilitation training. Combined with rehabilitation medicine knowledge and robot technology, rehabilitation evaluation of rehabilitation robot system is established will be an important research direction of the future development of rehabilitation robots, which will improve the patient's quality of rehabilitation training.

\section{REFERENCES}

[1] Lump, Burgar G. The MIME robotic system for upper-limb neuronrehabilitation : results from a clinical trial insubacute stroke. In : Proceedings of the 9th International Conference on Rehabilitation Robotics, Chicago, USA,511-514,2005.

[2] QinYin, BiSheng, WangFu-gen.Upper limb function commonly used evaluation methods and clinical application of cerebral apoplexy. Chinese Journal of Rehabilitation.Medicine.Vol.19, No.3,232233,2001 .

[3] Qiu Dong. Multi-indicator comprehensive evaluation method of system analysis. Beijing: China statistics press, 1991.

[4] Burgar C G, Lum P S. ShorPC. Development of Robots for RehabilitationTherapy:ThePaloAltoVA/Stanford,Experience.Journal RehabilitationResearch Development.Vol.37,No.6, 663-673,2000.

[5] Zou Zhi-yong. Engineering machinery maintenance status quo and countermeasure study. Xi 'an: chang 'an university, 2002.

[6] Huang Hong-zhong. Mechanical design fuzzy optimization theory and application. Science press, 1997.

[7] Xu Guo-zheng, patriotic song, Li Hui-jun. Upper limbs rehabilitation robot impedance based on fuzzy logic control experimental study . Robot, Vol. 32, No. 6,: 792-798, 2010.

[8] LU Xu-xiang, LI Lu-ping. Estimation for operating state of condenser based on fuzzy synthesis judgment . Turbine Technology,Vol.43,No.5,301-303,2001. 